\title{
Kaposi's sarcoma in acquired immune deficiency syndrome (AIDS)
}

\author{
ND FRANCIS,* JM PARKIN, $†$ J WEBER, $\ddagger$ AW BOYLSTON* \\ From the *Departments of Experimental Pathology and †Immunology, St Mary's Hospital Medical School, and \\ the $\ddagger$ Chester Beatty Institute, London
}

SUMMARY Of 22 patients with Kaposi's sarcoma, 16 had the acquired immune deficiency syndrome (AIDS). The histological pattern in AIDS differs from the more familiar classical Kaposi's sarcoma. The features most useful in making the diagnosis are: dissection of collagen; lymphatic vessel like spaces; angiomatoid lesions; premonitory sign; and spindle cell proliferation. It is important to examine multiple levels of small biopsy specimens and to be cautious in making the diagnosis of patch Kaposi's sarcoma in the presence of recent or healed ulceration and at sites of previous trauma. Only four of 16 patients with AIDS had evidence of systemic Kaposi's sarcoma, supporting the view that Kaposi's sarcoma in AIDS does not necessarily have an aggressive clinical course.

The acquired immune deficiency syndrome (AIDS) first recognised in $1981^{1}$ is characterised by unusual tumours and infections. It is now thought to be secondary to infection with human $\mathrm{T}$ cell lymphotropic virus type III (HTLV III/LAV). ${ }^{2} 3$

Kaposi's sarcoma is one of the criteria for the diagnosis of AIDS and may often be the presenting feature. In this group of patients the histological features differed from those of Kaposi's sarcoma, as described in standard dermatopathology textbooks. ${ }^{45}$ In particular, these lesions may resemble granulation tissue, a reactive process, or stasis dermatitis. ${ }^{6}$ An accurate diagnosis is therefore important.

Sixteen patients with Kaposi's sarcoma secondary to AIDS were studied. We examined the histopathological features in detail.

\section{Patients and methods}

Biopsy specimens of twenty two patients with Kaposi's sarcoma seen in the department of pathology at St Mary's Hospital between March 1982 and August 1985 were reviewed. Sixteen of these occurred in patients with AIDS. Thirty skin biopsy specimens (21 from patients with AIDS, nine from patients without AIDS) and four biopsies from other sites (one trachea, two rectal, one mouth) in three of the patients with AIDS were examined.

The age and sex, site of biopsy, HTLV III antibody

Accepted for publication 7 January 1986 state, evidence of sexually transmitted and opportunistic infections, and the patient's overall condition were reviewed. The median period of follow up was 14 months (range 0.5-42 months).

We attempted to classify lesions as patch, plaque, and nodular Kaposi's sarcoma. As the borderline between patch and plaque is not well defined we used the following definitions of each type:

Patch These are diffuse lesions without collections of spindle cells forming solid nodules.

Plaque These are lesions with aggregates of spindle cells either in poorly defined or well defined tumours. (These were often seen in conjunction with features of the patch stage.)

Nodular These are lesions with well defined rounded border forming solid nodules consisting of spindle cells with or without slit like vascular spaces.

In some cases a mixed pattern was seen, particularly of patch and plaque type lesions.

Each biopsy specimen was also scored for the presence or absence of the following histological fea-

Table 1 Opportunistic infections in patients with AIDS and Kaposi's sarcoma

\begin{tabular}{ll}
\hline & No of patients* \\
\hline Candidiasis (oral or oesophageal) & 7 \\
Pneumocystis carinii & 5 \\
Cytomegalovirus & 2 \\
Cryptococcus & 1 \\
Mycobacterium tuberculosis & 1 \\
\hline * Several patients had multiple infection
\end{tabular}


Table 2 Histological features seen in Kaposi's sarcoma in 21 skin biopsy specimens from 16 patients with AIDS

\begin{tabular}{ll}
\hline Histological feature & Prevalence \\
\hline Dissection of collagen & 19 \\
Extravasation of red blood cells & 19 \\
Inflammatory infiltrate & 18 \\
Spindle cells & 17 \\
Premonitory sign & 13 \\
Lymphatic vessel like spaces & 12 \\
Angiomatoid lesions & 11 \\
\hline
\end{tabular}

tures: dissection of collagen, premonitory sign (jagged irregular branching spaces around an otherwise normal dermal vessel), ${ }^{6}$ lymphatic vessel like spaces, angiomatoid lesions, spindle cell proliferation, and extravasation of red blood cells. No attempt was made to classify the tumours according to Clark's levels. $^{7}$

\section{Results}

PATIENTS WITH AIDS $(\mathrm{n}=16)$

\section{Clinical findings}

All the patients with AIDS were male homosexuals, and 15 were positive for HTLV III antibody (one unsuitable for analysis). Presenting features varied, but most patients presented with Kaposi's sarcoma as the first manifestation of AIDS. One patient presented with persistent generalised lymphadenopathy and was found to have systemic Castleman's disease nine months before developing Kaposi's sarcoma.

Four patients had disseminated non-cutaneous

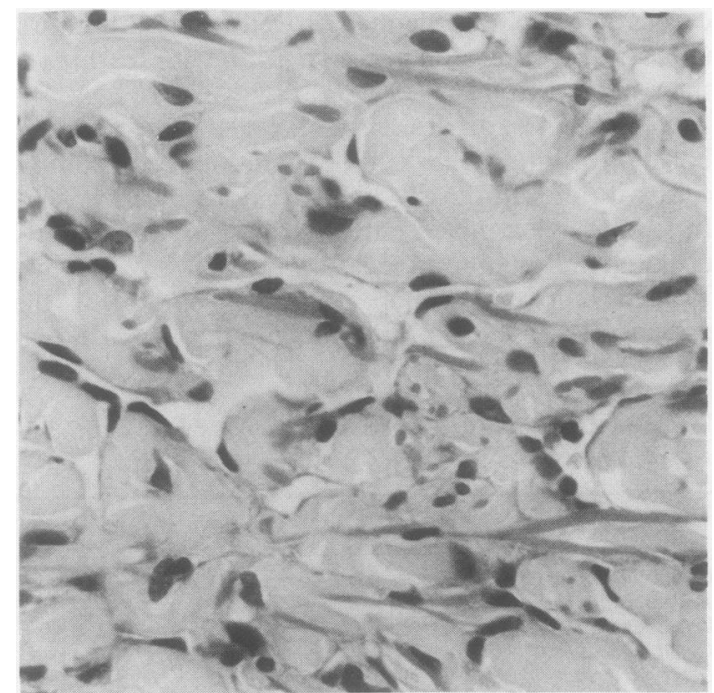

Fig. 1 Dissection of collagen. Original magnification $\times 320$.

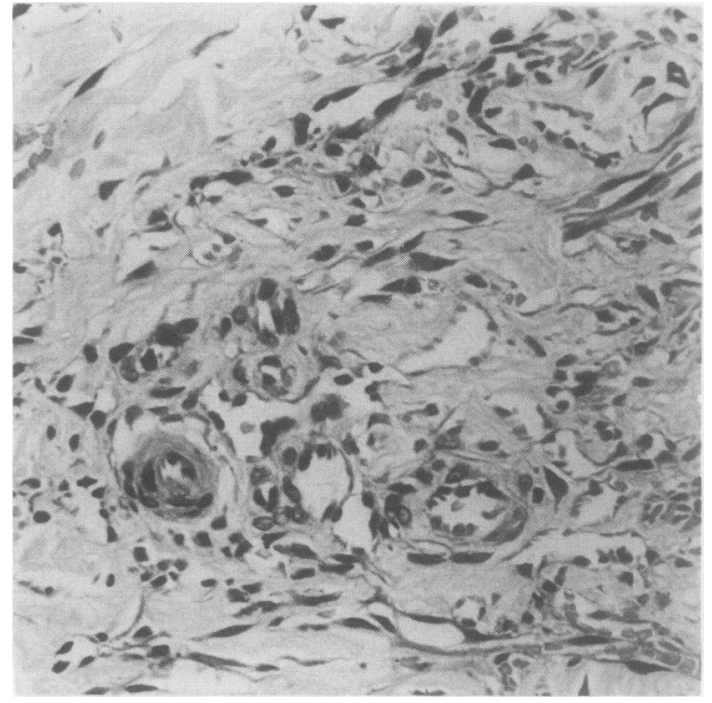

Fig. 2 Premonitory sign. Original magnification $\times 252$.

Kaposi's sarcoma (confirmed by biopsy): one lymphoid, one tracheal, one oral, one rectal and lymphoid. Three of these patients died of Pneumocystis carinii pneumonia. Three other patients died; two from biopsy confirmed and one from presumptive Pneumocystis. Seven patients had Kaposi's sarcoma without and nine with opportunistic infection. Oral candidiasis was the most common infection (Table 1).

\section{Histology}

Table 2 shows the number and distribution of indi-

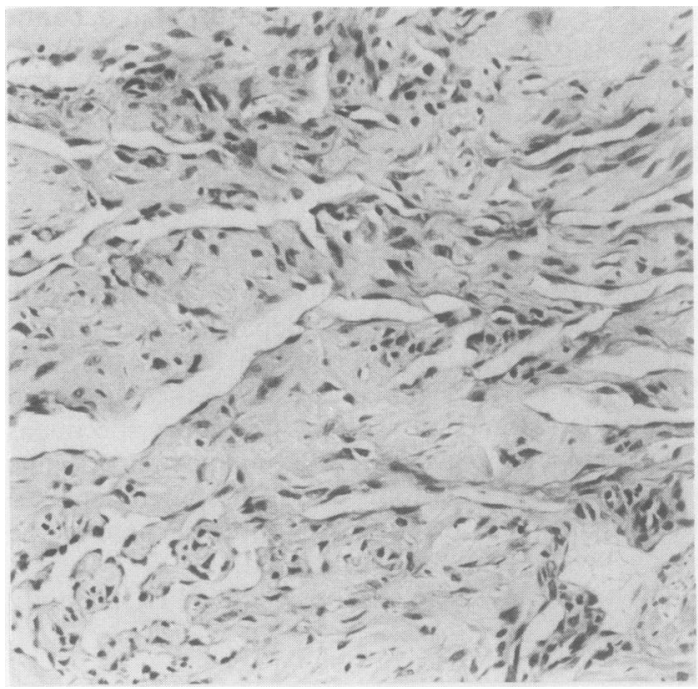

Fig. 3 Lymphatic like spaces. Original magnification $\times 125$. 


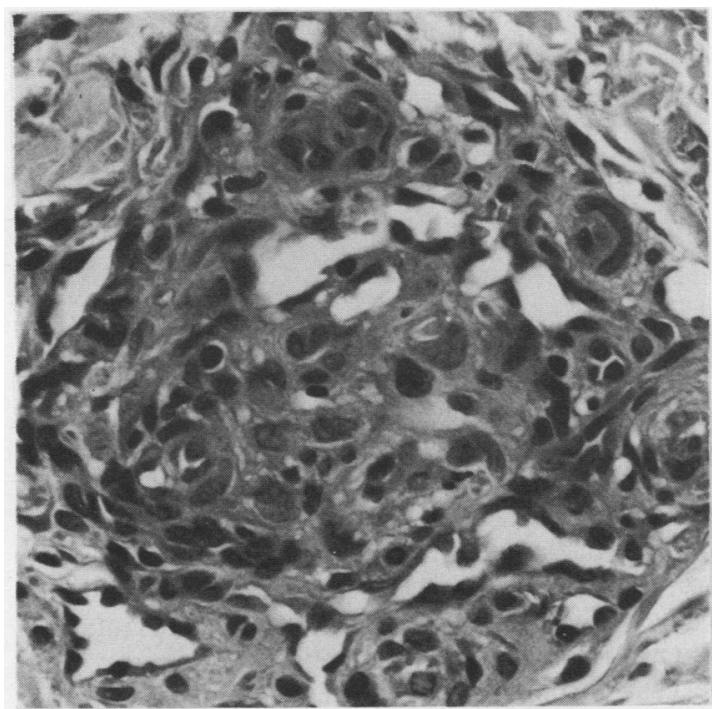

Fig. 4 Angiomatoid lesions. Original magnification $\times 320$.

vidual features in the Kaposi's sarcoma lesions. The features we found the most useful were:

1 Dissection of collagen by irregular small branching spaces, lined by flattened endothelial cells showing mild or no cellular atypia (Fig. 1).

2 Premonitory sign proliferation of jagged irregular endothelial lined spaces arising around normal dermal vessels (Fig. 2).

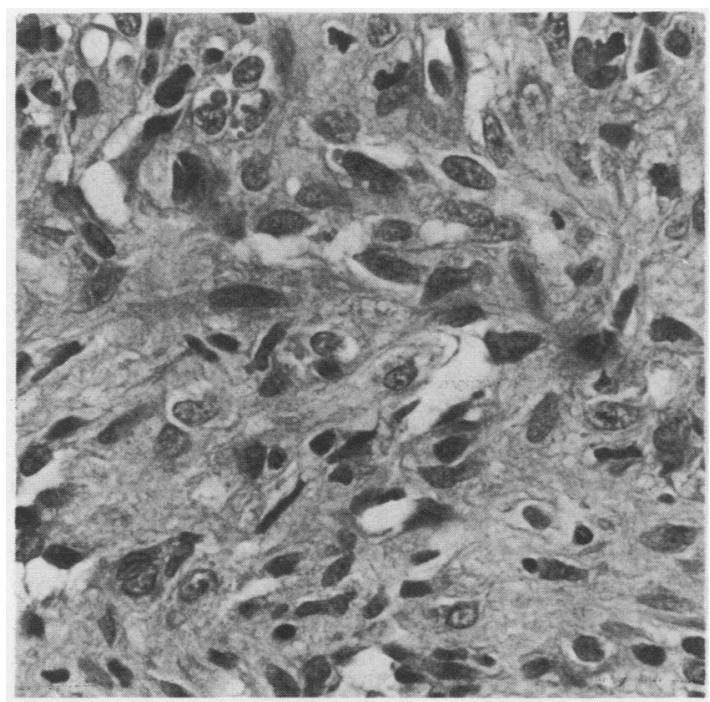

Fig. 5 Spindle cells in plaque. Original magnification $\times 500$.

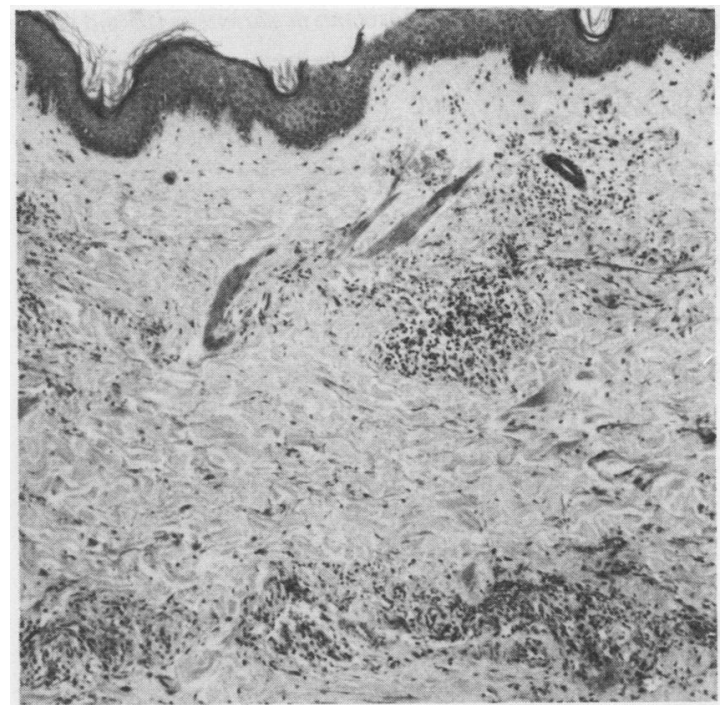

Fig. 6 Patch Kaposi's sarcoma. Original magnification $\times 33$.

3 Lymphatic vessel like spaces: dilated moderately extensive endothelial lined spaces, not containing red cells (Fig. 3).

4 Angiomatoid lesions: collections of small vascular spaces clumped together, often lined by prominent ("hob-nail") endothelial cells and surrounded by small numbers of proliferating spindle cells (Fig. 4).

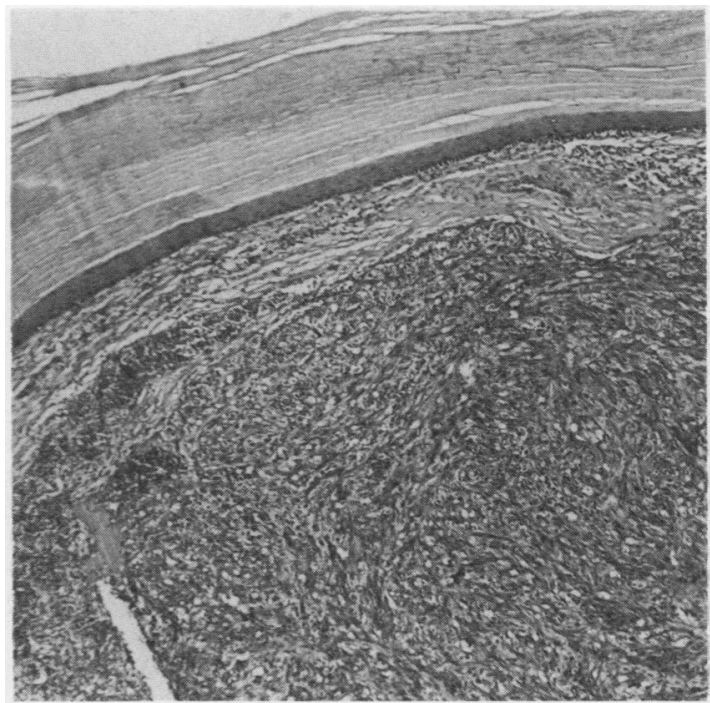

Fig. 7 Classical nodular Kaposi's sarcoma (low power). Original magnification $\times 50$. 
Table 3 Type of Kaposi's sarcoma in patients with and without AIDS

\begin{tabular}{|c|c|c|c|c|c|}
\hline \multirow{2}{*}{$\begin{array}{l}\text { Patients } \\
\text { (age in years) }\end{array}$} & \multirow[t]{2}{*}{ No } & \multirow{2}{*}{$\begin{array}{l}\text { Skin } \\
\text { biopsies }\end{array}$} & \multicolumn{3}{|c|}{ Overall pattern of Kaposi's sarcoma } \\
\hline & & & Patch & Plaque & Classical nodular \\
\hline \multirow{3}{*}{$\begin{array}{l}\text { With AIDS } \\
27-48 \\
\text { Without AIDS } \\
\text { 46-84 } \\
\text { Total }\end{array}$} & 16 & 21 & 18 & 2 & 1 \\
\hline & 6 & 9 & & 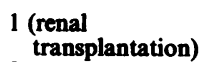 & 8 \\
\hline & 22 & 30 & 18 & 3 & 9 \\
\hline
\end{tabular}

5 Spindle cells. These comprised two types: elongated cells with narrow darker nuclei and no obvious nucleolus and a more florid type with an open nucleus and nucleolus. These showed the same morphology as the spindle cells in classical nodular Kaposi's sarcoma. (Fig. 5).

In addition, extravasated red cells, haemosiderin, and an inflammatory infiltrate (of lymphocytes and plasma cells) were found in most cases.

On low power examination the appearances of Kaposi's sarcoma in AIDS (Fig. 6) differed from the classical nodular type (Fig. 7), having a much more diffuse pattern. Table 3 shows the results of the overall classification of this type of Kaposi's sarcoma compared with that of the non-AIDS cases. Tumour was found in the dermis in all cases, and in only two was the subcutaneous tissue affected.

\section{PATIENTS WITHOUT AIDS $(\mathrm{n}=6)$}

\section{Clinical findings}

All except one patient presented with classical Kaposi's sarcoma nodule (three) on limb extremities. The patient who did not had undergone a renal trans-

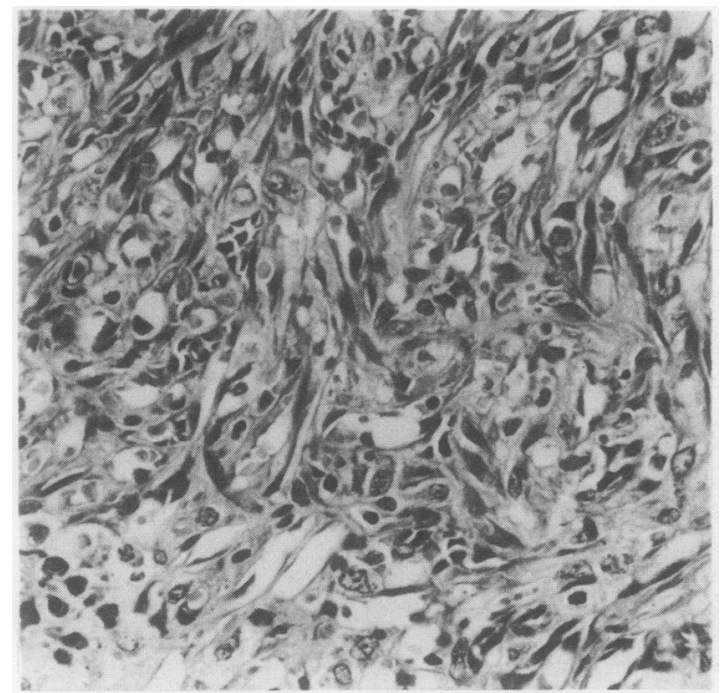

Fig. 8 Classical nodular Kaposi's sarcoma (higher power). Original magnification $\times 33$. plantation and developed a tumour in the operation scar. One patient was a West Indian living in England, two were elderly Jewish patients, and one of these was the only woman in this study, and two were referral cases from the Comoro Islands.

In all but the renal transplantation patient the picture was that of classical nodular Kaposi's sarcoma (Table 3, Figs. 7 and 8). In the renal transplantation patient the lesion was highly cellular with many spindle cells forming a poorly defined but widespread tumour. It closely resembled the advanced plaque stage of Kaposi's sarcoma in the patients with AIDS, but it was larger.

\section{Discussion}

At the time of writing there have been 205 cases of AIDS and 114 deaths as a result in the United Kingdom. Fifty two (25\%) patients had Kaposi's sarcoma alone (25 deaths) and a further 13 had Kaposi's sarcoma with Pneumocystis infection (10 deaths). The patients with AIDS and Kaposi's sarcoma comprise one third (Public Health Laboratory Services, unpublished report).

Analysis of our patients with Kaposi's sarcoma and AIDS shows only one case of classical nodular Kaposi's sarcoma. All the other cases were small, diffuse, poorly defined lesions, which on low power view may be misleadingly innocuous, and, as previously pointed out by Templeton $^{8}$ and Ackerman, ${ }^{9}$ may resemble a stasis dermatitis.

The four features that we found most useful in making the diagnosis were dissection of dermal collagen, lymphatic vessel like spaces in the dermis, angiomatoid lesions, and the premonitory sign. Other authors $^{9-11}$ have emphasised the first of these features, and this was found in 19 of our 21 biopsy specimens, including the peripheral zone of the one case of nodular Kaposi's sarcoma.

Spindle cells were seen in many cases, but only in small numbers in the patch lesion, becoming more prominent in the plaque and irregular tumour lesions. Although inflammatory cells were found in most cases, they were not usually a prominent feature, and together with red cell extravasation were considered 
to be non-specific and therefore of no particular value in the diagnosis of Kaposi's sarcoma. This contrasts with previous reports that have emphasised the presence of inflammatory (particularly plasma) cells 6910

We also found minor degrees of endothelial cell atypia (cuboidal and "hob-nail" appearances) in the angiomatoid lesions, which also contrast with reports of absence of cellular atypia in patch and plaque lesions. $^{6}$

Lymphatic vessel like spaces have been reported in Kaposi's sarcoma, whether or not they were associated with AIDS. ${ }^{1213}$ We found this feature in more than $50 \%$ of the biopsy specimens from patients with AIDS.

Although the features we report are not widely recognised as occurring in African or European Kaposi's sarcoma that is not associated with AIDS, they do occur and have been reported in "early" lesions ${ }^{8}$ (NF; personal observation). We therefore agree that Kaposi's sarcoma in AIDS is not a different tumour but part of the spectrum of histological variation. We have not seen a case that has developed from a patch through plaque to nodule, or developed directly from a patch to a nodule. Therefore, although circumstantial evidence suggests that the patch precedes the plaque, or nodule, this may not be a well ordered evolutionary progression. None of the individual histological features or overall type of the tumour seemed to be prognostically important. It is therefore probably not necessary to distinguish patch, plaque, and nodule, apart from the accurate recording of features for future study.

An important practical point is the necessity to examine multiple levels of small biopsy specimens to find diagnostic features. We would recommend a minimum of six levels on a punch biopsy of a suspicious lesion. A second practical point is the close resemblance of patch Kaposi's sarcoma to granulation tissue, and biopsies from areas of healed or recent ulceration and sites of trauma should be interpreted with extreme caution.

Only four patients developed visceral or disseminated Kaposi's sarcoma. We have had no cases of primary lymph node Kaposi's sarcoma without cutaneous tumour. There is a discrepancy between our findings and a recent report of a necropsy study of 56 deaths from AIDS in New York, ${ }^{14}$ in which $95 \%$ of the patients had disseminated Kaposi's sarcoma. The reasons for this difference could be that we do not perform necropsies on patients with AIDS and are, therefore, probably missing subclinical disseminated Kaposi's sarcoma and that the New York study only looked at deaths from AIDS and was therefore dealing with the patients whose general condition and immunological competence was most extensively impaired.
Our patients with Kaposi's sarcoma alone seemed to have a better prognosis, as has been suggested by a previous report, ${ }^{16}$ and the most important event seems to be the development of opportunistic infections. Our experience is reflected in the figures for the United Kingdom as a whole, which show a $48 \%$ mortality in patients with Kaposi's sarcoma alone and a higher mortality in patients with Kaposi's sarcoma and Pneumocystis infection (77\%); other opportunistic infections account for (59\%) and Pneumocystis infection alone $(53 \%)$. These proportions are very similar to figures obtained for AIDS cases in the United States. ${ }^{16}$ (and Public Health Laboratory Service, unpublished report.)

In conclusion, Kaposi's sarcoma in AIDS presents a problem of diagnosis for the histopathologist, mainly because the features differ from those usually seen in classical, endemic, or sporadic Kaposi's sarcoma. The tumour does not necessarily have a uniformly poor prognosis or have the aggressive behaviour that has been suggested. In our experience Kaposi's sarcoma in AIDS does not behave like the lymphadenopathic form seen in African children. ${ }^{17}$

\section{Addendum}

Since January 1986 another patient with AIDS and Kaposi's sarcoma has died of Pneumocystis pneumonia without clinical evidence of disseminated noncutaneous Kaposi's sarcoma.

A further three patients with AIDS have been diagnosed; all were HTLV III antibody positive and had Kaposi's sarcoma confirmed by biopsy (two cutaneous and one oral). Both cutaneous lesions were patch stage and showed angiomatoid lesions, inflammatory cells (mild), premonitary sign, lymphatic like spaces, and dissection of collagen (in one). One case showed classical hyaline droplets in the cytoplasm of cells forming the angiomatoid lesion.

The oral Kaposi's sarcoma was of the plaque stage.

We thank Mrs P Dodi and Miss V Newnham for their work on the manuscript.

\section{References}

${ }^{1}$ Centers for Disease Control. Kaposi's sarcoma and pneumocystis pneumonia among homosexual men-New York City and California. MMWR 1981;30:305-8.

${ }^{2}$ Gallo RC, Salahuddin SZ, Popovic M, et al. Frequent detection and isolation of cytopathic retroviruses (HTLV III) from patients with AIDS and at risk from AIDS. Science 1984; 224:500-3.

${ }^{3}$ NIH Conference. Moderator Fauci AS. The acquired immunedeficiency syndrome: an update. Ann Intern Med 1985;102: 800-13.

${ }^{4}$ Lever WF, Schaumburg-Lever G. Histopathology of the skin. 6th ed. Philadelphia: JB Lippincott, 1983.

${ }^{5}$ Mackie R. Milne's dermatopathology. 2nd ed. London: Edward Arnold, 1984. 
${ }^{6}$ Gottlieb GJ, Ackerman AB. An extensively disseminated form in young homosexual men. Hum Pathol 1982;13:882-92.

${ }^{7}$ Clark WH, Fromm L, Bernadino LA, Mihm MC. The histogenesis and biological behaviour of primary malignant melanoma of the skin. Cancer Res 1969;29:705-26.

${ }^{8}$ Templeton AC. In: Somers SC, ed. Kaposi's sarcoma. Pathology annual. New York: Appleton Century Crofts, 1981.

${ }^{9}$ Ackerman AB. Subtle clues to diagnosis by conventional microscopy. The patch stage of Kaposi's sarcoma. Am J Dermatopathol 1979;1:165-73.

${ }^{10}$ Blumenfield W, Egbert BM, Sagelbiel RW. Differential diagnosis of Kaposi's sarcoma. Arch Pathol Lab Med 1985;109:123-7.

${ }^{11}$ Beckstead JH, Wood GS, Fletcher V. Evidence for the origin of Kaposi's sarcoma from lymphatic endothelium. Am J Pathol 1985;119:294-300.

${ }^{12}$ Smith N. AIDS, Kaposi's sarcoma and the dermatologist. J Soc Med 1985;78:97-9.
${ }^{13}$ Gange RW, Wilson-Jones E. Lymphangioma-like Kaposi's sarcoma. Br J Dermatol 1979;100:327-34.

${ }^{14}$ Niedt GW, Schinella RA. Acquired immunodeficiency syndrome. Clinicopathological study of 56 autopsies. Arch Pathol Lab Med 1985;109:727-34.

${ }^{15}$ Rivin BE, Monbe JM, Hubschman BP, Thomas PA. Aids outcome: a first follow up. New Engl J Med 1984;311:857.

${ }^{16}$ Centers for Disease Control. Aids activity weekly surveillance Report, August 191985.

${ }^{17}$ Slavin GH, Cameron McD, Forbes C, Morton Mitchell R. Kaposi's sarcoma in east African children. J Pathol 1970: 187-99.

Requests for reprints to: ND Francis, Department of Experimental Pathology, St Mary's Hospital Medical School, Norfolk Place, London W2 IPG, England. 